\title{
CRISIS DEL DERECHO A LA VERDAD EN MÉXICO
}

\section{CRISE DO DIREITO À VERDADE NO MÉXICO}

\section{CRISIS OF THE RIGHT TO TRUTH IN MEXICO}

\author{
Alfonso Jaime Martínez LazCANo \\ https://orcid.org/0000-0003-0367-4716 / lazcanoalf14@hotmail.com \\ Universidad de Ciencias y Artes de Chiapas. \\ Chiapas, México.
}

\begin{abstract}
RESUMEN
Las redes sociales han servido para dar espacio a una serie de ideas que antes no tenían como expresarse, cualquier persona puede convertirse en un generador de información y difundirla, aunado a que la tecnología facilita alterar contenidos de documentos y fotografías, lo que cambia radicalmente la vida de los medios tradicionales que se convirtieron en su momento en los historiadores oficiales, sin embargo este fenómeno ha llegado a generar un exceso de información, muchas veces inexistentes, con la finalidad de manipular la opinión por medio de noticias falsas, parciales o segadas, con un grave deterioro al sistema democrático al trasgredir el derecho a la información que debe ser serio, oportuno y veraz. Este fenómeno se viene a sumar a otra serie de factores que atentan contra el derecho a libertad de expresión e información en diversos campos de la sociedad.
\end{abstract}

Palabras clave: Libertad de expresión; libertad de prensa; noticias falsas; periodismo.

\section{ABSTRACT}

The networks have served to give space to a series of ideas that did not have how to express themselves before, anyone can become an information generator and spread it, coupled with the fact that technology facilitates altering the contents of documents and photographs, which changes radically the life of the traditional media that at the time became the official historians, however this phenomenon has come to generate an excess of information, many nonexistent, in order to manipulate the opinion through false, partial or reaped news, with a serious deterioration to the democratic system by transgressing the right to information that must be serious, timely and truthful. This phenomenon is added to another series of factors that undermine the right to freedom of expression and information in various fields of society.

Keywords: Freedom of expression; freedom of the press; fake news; journalism.

\section{RESUMO}

As redes sociais serviram para dar espaço a uma série de ideias que não tinham como se expressar antes, qualquer pessoa pode se tornar um gerador de informações e divulgá-las, juntamente com o fato de que a tecnologia facilita a alteração do conteúdo de documentos e de fotografias, que muda radicalmente a vida da mídia tradicional que, em sua época, se tornou historiadora oficial, porém esse fenômeno acabou gerando excesso de informações, muitas inexistentes, para manipular a opinião por meio de notícias falsas, parciais ou colhidas, com uma grave deterioração do sistema democrático, transgredindo o direito a informações que devem ser sérias, oportunas e verdadeiras. Esse fenômeno é adicionado a outra série de fatores que comprometem o direito à liberdade de expressão e informação em vários campos da sociedade.

Palavras-chave: Liberdade de expressão; liberdade de imprensa; notícias falsas; jornalismo. 


\section{SUMÁRIO}

INTRODUCCIÓN. 1 LIBERTAD DE PENSAMIENTO; 2 LIBERTAD DE EXPRESIÓN; 2.1 Dimensiones de la libertad de expresión; 2.2 Límites; 2.3 Prohibiciones; 2.4 Responsabilidades por difusión maliciosa de las empresas editorial; 2.5 Medios indirectos de restricción; 3 LIBERTAD DE PRENSA; 4 DERECHO A LA INFORMACIÓN; 5 EJERCÍCIO DEL PERIODISMO EN MÉXICO; 5.1 Plata; 5.2 Plomo; 5.3 Mecanismos de protección a los periodistas; 6 NOTICIAS FALSAS; 7 EL DERECHO A LA VERDAD; 7.1 Credibilidad CONCLUSIÓN. REFERENCIAS

Una mentira puede viajar por medio mundo mientras la verdad está poniéndose los zapatos.

Mark Twain

\section{INTRODUCCIÓN}

Ante el común denominador de pretender manipular las voluntades de las mayorías, la información o desinformación se ha convertido en una herramienta fundamental para este propósito. El hecho de comunicar con veracidad un suceso cada vez es más complicando, existen muchos factores que tienen como fin imponer una "verdad" u ocultar información, los grupos del crimen organizado y políticos utilizan la política de plata o plomo para sobornar o coptar a los medios y a los periodistas, otro factor simultáneo se da a raíz de la facilidad de difundir a través de la web noticias falsas (fake news) o pos verdades, la utilización de robots (trolls y bots) para ampliar cobertura y aparentar apoyo con fines de propaganda política.

Aunado, a que los servidores públicos encargados de investigar hechos que pueden constituir delitos graves de violación de derechos humanos, no sólo esconden información, sino hay la intención de distorsionar la interpretación de los hechos para proteger a los culpables, lo que genera un alto grado de impunidad en México.

Tan importante es la certeza de los sucesos que la verdad se ha convertido en un derecho humano.

Hay múltiples ejes interdependientes, que se entretejen: la libertad de pensamiento, la libertad de expresión, la libertad de prensa o de medios, el derecho a la información, todos cimientos de la democracia. 


\section{LIBERTAD DE PENSAMIENTO}

Una de las características esenciales del ser humano es el uso de la razón, que da la posibilidad de generar ideas y muchas de ellas sirven para trasformar la realidad. En lo individual es un derecho para que sin ataduras ni persecuciones se tenga la plena libertad para pensar sin limitación alguna, por ejemplo, el Estado no debe imponer una religión como oficial, someter a quien sea disidente a las opiniones de quienes ejercen el poder público, así el artículo 18 de la Declaración Universal de los Derechos Humanos, señala:

Toda persona tiene derecho a la libertad de pensamiento, de conciencia y de religión; este derecho incluye la libertad de cambiar de religión o de creencia, así como la libertad de manifestar su religión o su creencia, individual y colectivamente, tanto en público como en privado, por la enseñanza, la práctica, el culto y la observancia.

La libertad de pensamiento tiene que ver con el estilo de vida, con aspectos internos del hombre, como la moral, el culto religioso, el derecho a la libre investigación y discusión de las ideas, la libertad de cátedra, en síntesis con la cultura. La Declaración Universal de la UNESCO sobre la Diversidad Cultural ha establecido que:

La cultura debe ser considerada el conjunto de los rasgos distintivos espirituales y materiales, intelectuales y afectivos que caracterizan a una sociedad o a un grupo social y que abarca, además de las artes y las letras, los modos de vida, las maneras de vivir juntos, los sistemas de valores, las tradiciones y las creencias ${ }^{1}$.

Es complemento necesario del derecho al libre pensamiento el de libre expresión, pues no basta que una persona o grupo tenga diversas ideas sino que cuente con la posibilidad de difundirlas a través de diversos medios.

\footnotetext{
1 Definición conforme a las conclusiones de la Conferencia Mundial sobre las Políticas Culturales (MONDIACULT, México, 1982), de la Comisión Mundial de Cultura y Desarrollo (Nuestra Diversidad Creativa, 1995) y de la Conferencia Intergubernamental sobre Políticas Culturales para el Desarrollo (Estocolmo, 1998).
} 


\section{LIBERTAD DE EXPRESIÓN}

La libertad de expresión implica el poder decir lo que se piensa, y que no sea mermado este derecho, por un lado impidiéndolo y por otro castigándolo. Esta facultad tiene un impacto en su esfera individual, en lo social es la base también del derecho a la información.

En un sistema democrático la regla de oro es dar a conocer cualquier suceso que tenga trascendencia en la vida pública, como rendir informes, trasparentar procesos de decisión y permitir la disidencia, en síntesis que se conozcan los asuntos que son públicos.

La libertad de expresión es una piedra angular en la existencia misma de una sociedad democrática. Es indispensable para la formación de la opinión pública. Por ende, es posible afirmar que una sociedad que no está bien informada no es plenamente libre ${ }^{2}$. El artículo 19.1 del Pacto Internacional de Derechos Civiles y Políticos (PIDCP) dispone:

Nadie podrá ser molestado a causa de sus opiniones. 2. Toda persona tiene derecho a la libertad de expresión; este derecho comprende la libertad de buscar, recibir y difundir informaciones e ideas de toda índole, sin consideración de fronteras, ya sea oralmente, por escrito o en forma impresa o artística, o por cualquier otro procedimiento de su elección.

El artículo 4 de la Carta Interamericana Democrática dispone:

Son componentes fundamentales del ejercicio de la democracia la transparencia de las actividades gubernamentales, la probidad, la responsabilidad de los gobiernos en la gestión pública, el respeto por los derechos sociales y la libertad de expresión y de prensa.

El artículo 13 de la Convención Americana sobre Derechos Humanos (Convención ADH) versa sobre la libertad de pensamiento y de expresión, y dispone en su primer apartado:

Toda persona tiene derecho a la libertad de pensamiento y de expresión. Este derecho comprende la libertad de buscar, recibir y difundir informaciones e ideas de toda índole, sin consideración de fronteras ya sea oralmente, por escrito o en forma impresa o artística, o por cualquier otro procedimiento de su elección.

${ }^{2}$ CORTE IDH. La Colegiación Obligatoria de Periodistas. Opinión Consultiva OC-5/85. 


\subsection{Dimensiones de la libertad de expresión}

La Corte Interamericana de Derechos Humanos (Corte IDH) ha indicado que el artículo 13 de la Convención $\mathrm{ADH}$ ha señalado que la libertad de expresión tiene una dimensión individual y una dimensión social, de las cuales ha desprendido una serie de derechos que se encuentran protegidos, que ambas dimensiones poseen igual importancia y deben ser garantizadas plenamente en forma simultánea para dar efectividad total al derecho a la libertad de expresión. Para el ciudadano común tiene tanta importancia el conocimiento de la opinión ajena o de la información de que disponen otros como el derecho a difundir la propia. Es por ello que, a la luz de ambas dimensiones, la libertad de expresión requiere, por un lado, que nadie sea arbitrariamente menoscabado o impedido de manifestar su propio pensamiento y representa, por tanto, un derecho de cada individuo; pero implica también, por otro lado, un derecho colectivo a recibir cualquier información y a conocer la expresión del pensamiento ajeno 3 .

Para la Primera Sala de la Suprema Corte de Justicia de la Nación (SCJN), siguiendo el criterio de la Corte IDH ha determinado que la libertad de expresión y el derecho a la información son derechos funcionalmente centrales en un Estado constitucional y tienen una doble faceta: por un lado, aseguran a las personas espacios esenciales para el despliegue de su autonomía y, por otro, gozan de una vertiente pública, colectiva o institucional que los convierte en piezas básicas para el adecuado funcionamiento de la democracia representativa...lo cual exige que no sólo los individuos no vean impedidos la posibilidad de manifestarse libremente, sino también que se respete su derecho como miembros de un colectivo a recibir información y a conocer la expresión del pensamiento ajeno.

Así, tener plena libertad para expresar, recolectar, difundir y publicar informaciones e ideas es imprescindible no solamente como instancia esencial de autoexpresión y desarrollo individual, sino como condición para ejercer plenamente otros derechos fundamentales -el de asociarse y reunirse pacíficamente con cualquier objeto lícito, el derecho de petición o el derecho a votar y ser votado- y como elemento determinante de la calidad de la vida democrática en un país, pues si los ciudadanos no tienen plena seguridad de que el derecho los protege en su

\footnotetext{
${ }^{3}$ CORTE IDH. Caso Lagos del Campo Vs. Perú. Excepciones Preliminares, Fondo, Reparaciones y Costas.
} Sentencia de 31 de agosto de 2017. Serie C No. 340., Párrafo 89. 


\section{LDIREITO}

CRISIS DEL DERECHO A LA VERDAD EN MÉXICO

posibilidad de expresar y publicar libremente ideas y hechos, será imposible avanzar en la obtención de un cuerpo extenso de ciudadanos activos, críticos, comprometidos con los asuntos públicos, atentos al comportamiento y a las decisiones de los gobernantes, capaces de cumplir la función que les corresponde en un régimen democrático.

Por consiguiente, cuando un tribunal decide un caso de libertad de expresión, imprenta o información no sólo afecta las pretensiones de las partes en un litigio concreto, sino también el grado al que en un país quedará asegurada la libre circulación de noticias, ideas y opiniones, así como el más amplio acceso a la información por parte de la sociedad en su conjunto, condiciones todas ellas indispensables para el adecuado funcionamiento de la democracia representa ${ }^{4}$.

\subsection{Limites}

La libertad de expresión no está sujeto a ningún requisito previo para su difusión, sino que una vez ejercido el derecho, sí existen responsabilidades por la información es factible en lo posterior reclamar por quien se sienta aludido o afectado por el contenido de la información. De esta manera el artículo 13 de la Convención ADH, en el segundo punto dispone: El ejercicio del derecho de libertad de pensamiento y de expresión no puede estar sujeto a previa censura sino a responsabilidades ulteriores las que deben estar expresamente fijadas por la ley y ser necesarias para asegurar: a) Asegurar el respeto a los derechos o a la reputación de los demás, y b) La protección de la seguridad nacional, el orden público o la salud o la moral públicas:

La Corte IDH debe encontrar un equilibrio entre la vida privada y la libertad de expresión que, sin ser absolutos, son dos derechos fundamentales garantizados en la Convención Americana y de la mayor importancia en una sociedad democrática. El Tribunal recuerda que el ejercicio de cada derecho fundamental tiene que hacerse con respeto y salvaguarda de los demás derechos fundamentales. En ese proceso de armonización le cabe un papel medular al Estado buscando establecer las responsabilidades y sanciones que fueren necesarias para obtener tal propósito. La necesidad de proteger los derechos que pudieran verse afectados por un ejercicio abusivo de la libertad de expresión, requiere la debida observancia de los límites fijados a este respecto por la propia Convención ${ }^{5}$.

${ }^{4}$ Tesis: 1a. CCXV/2009, Semanario Judicial de la Federación y su Gaceta, Tomo XXX, diciembre de 2009, p. 287.

${ }^{5}$ CORTE IDH. Caso Fontevecchia y D Amico Vs. Argentina. Fondo, Reparaciones y Costas. Sentencia de 29 de noviembre de 2011. Serie C No. 238, Párrafo 50. 


\subsection{Prohibiciones}

El numeral 20 del PIDCP establece prohibiciones a la libertad de pensamiento y de expresión, en los siguientes supuestos: 1 . Toda propaganda en favor de la guerra estará prohibida por la ley; 2. Toda apología del odio nacional, racial o religioso que constituya incitación a la discriminación, la hostilidad o la violencia estará prohibida por la ley.

Un punto importante es la posibilidad de dar cabida a todas las voces, permitir o facilitar que se difundan una pluralidad de ideas, lo cual se ve mermado cuando los medios de comunicación están controlados por monopolios u oligopolios, lo cual es evidente que disminuye la calidad de la democracia de los Estados:

La Corte IDH ha indicado que "la libertad de expresión se puede ver también afectada sin la intervención directa de la acción estatal. Tal supuesto podría llegar a configurarse, por ejemplo, cuando por efecto de la existencia de monopolios u oligopolios en la propiedad de los medios de comunicación, se establecen en la práctica 'medios encaminados a impedir la comunicación y la circulación de ideas y opiniones"'. Sobre este punto, el artículo 12 de la Declaración de Principios sobre la Libertad de Expresión indica que "[l]os monopolios u oligopolios en la propiedad y control de los medios de comunicación deben estar sujetos a leyes antimonopólicas por cuanto conspiran contra la democracia al restringir la pluralidad y diversidad que asegura el pleno ejercicio del derecho a la información de los ciudadanos. En ningún caso estas leyes deben ser exclusivas de los medios de comunicación. Las asignaciones de radio y televisión deben considerar criterios democráticos que garanticen una igualdad de oportunidades para todos los individuos en el acceso a los mismos ${ }^{6} . "$

Los espectáculos públicos pueden ser sometidos por la ley a censura previa, con el exclusivo objeto de regular el acceso a ellos para la protección moral de la infancia y la adolescencia.

Estará prohibida por la ley toda propaganda en favor de la guerra y toda apología del odio nacional, racial o religioso que constituyan incitaciones a la violencia o cualquier otra acción ilegal similar contra cualquier persona o grupo de personas, por ningún motivo, inclusive los de raza, religión, idioma u origen nacional.

\footnotetext{
${ }^{6}$ CORTE IDH. Caso Granier y otros (Radio Caracas Televisión) Vs. Venezuela. Excepciones Preliminares, Fondo, Reparaciones y Costas. Sentencia de 22 de junio de 2015. Serie C No. 293, Párrafo 143.
} 


\subsection{Responsabilidades por difusión maliciosa de las empresas editorial}

Respecto de la responsabilidad de objetiva de las empresas editoriales la Primera Sala de la SCJN ha establecido como regla general la ausencia de imputación con sus excepciones concretas, sancionando a los órganos directivos o empresas editoriales, conjuntamente con los autores, cuando afecten el honor, la vida privada de las personas, la propia imagen, etcétera, a consecuencia de los materiales que se reproduzcan en los medios de comunicación.

Cada uno de los siguientes supuestos no se describe especies de responsabilidad objetiva sino subjetiva, porque existe dolo en ellas:

A. Existencia de un acuerdo de voluntades, expreso o tácito, entre la empresa editorial y el autor, en el que la primera se haya reservado su derecho de revisar previamente el contenido aportado por el segundo, como requisito establecido en el contrato de edición literaria, con base en las disposiciones de la Ley Federal del Derecho de Autor ${ }^{7}$.

B. Cuando la empresa editorial intencionalmente busca dañar o afectar, acorde a lo dispuesto por el artículo 2106 del Código Civil Federal y sus correlativos de las entidades de la República, así como diversos principios de los actos jurídicos propios, relativos a que nadie puede beneficiarse de su propio dolo. Para evitar legitimar el abuso del derecho, debe recurrirse al análisis de su organización normativa y funcional, vista externamente o mediante el corrimiento del velo corporativo, cuando ello sea estrictamente necesario, con base en los hechos y las pruebas aportadas por el afectado, que pueden complementarse con las recabadas oficiosamente por el juzgador, cuando así proceda.

C. Culpa inexcusable de la empresa editorial, presente en los casos de información notoriamente falsa; la que carece claramente de fuentes comprobables, a pesar de haberse manejado como "investigación"; la que se aparta de las reglas de la lógica, del sentido común, o la que parte de premisas clara, evidente y rotundamente indemostrables, que fácilmente se adviertan por cualquier persona, como sucede, verbigracia, cuando se derivan de revelaciones de videntes o seres divinos. En este supuesto, para determinar la responsabilidad, es imprescindible

\footnotetext{
${ }^{7}$ Esta situación implica que la editorial realiza un análisis previo del contenido de la información, con la finalidad de determinar si decide o no publicarla. Ese análisis no se traduce en una previa censura, ni se les impone la obligación de revisar y seleccionar contenidos y decidir qué notas pueden o no publicar, porque esa actividad se lleva a cabo en cumplimiento a los derechos y obligaciones contractuales.
} 
que el demandante contribuya aportando los hechos claros, precisos y concisos desde su demanda y cumpla su carga probatoria.

D. Cuando es dueña o titular de los derechos de publicación, de manera que, pueda reimprimir o autorizar a otros la reproducción del contenido, ya declarado ilícito, en otros medios de difusión. En este caso, la editorial podría pretender ejercer sus derechos contractuales, y así poner en tela de juicio los derechos del afectado para defenderse, porque ya no podría demandarse de nueva cuenta al autor, en virtud de que la reimpresión o nueva publicación no le serán atribuibles. La situación se agrava cuando la información permanece en Internet por tiempo indefinido, pues si no se vincula a la editorial, se pondría en duda su obligación consecuencial de eliminar los registros digitales y dejarla al alcance de cualquier cibernauta, por lo que el acto ilícito seguiría produciendo efectos y consecuencias en el patrimonio moral del afectado.

E. Por discriminación e inequidad en el cumplimiento de la condena. En efecto, estas empresas desempeñan una actividad lucrativa, por lo cual existe la presunción legal de que obtuvieron ganancias con la publicación de la información ilícita. La mercantilidad de sus actos implica que si solamente se condena al autor, en términos del artículo 39 de la Ley de Responsabilidad Civil para la Protección del Derecho a la Vida Privada, el Honor y la Propia Imagen en el Distrito Federal, ahora Ciudad de México, se propiciaría:

a) Discriminar subjetivamente al autor frente a la editorial, porque a pesar de que ambos lucraron con el mismo acto ilícito, solamente el primero tendrá que soportar la condena, en contravención al artículo 10. constitucional; y

b) Enriquecer ilícitamente a la editorial, al lucrar con la publicación de la sentencia condenatoria a costa del autor, ganancia que puede ser mucho mayor acorde al espacio necesario para difundir la resolución condenatoria.

F. El enfoque de la información, por el formato o estilo del diseño gráfico ${ }^{8}$.

\subsection{Medios indirectos de restricción}

El mismo precepto 13 de la Convención ADH en los puntos 3, 4 y 5 dispone:

\footnotetext{
${ }^{8}$ Tesis: I.40.C.71 C (10a.), Gaceta del Semanario Judicial de la Federación, Libro 65, abril de 2019, Tomo III, p. 2005.
} 
No se puede restringir el derecho de expresión por medios indirectos tales como el abuso de controles oficiales o particulares de papel para periódicos, de frecuencias radioeléctricas, o de enseres y aparatos usados en la difusión de información o por cualesquiera otros medios encaminados a impedir la comunicación y la circulación de ideas y opiniones.

\section{LIBERTAD DE PRENSA}

La libertad de prensa es el derecho de difundir a través de diversos géneros de periodismo: noticias, opiniones, reportajes, entrevistas, etcétera, que permiten conocer hechos e interpretaciones de éstos por los periodistas:

La diferencia entre libertad de expresión y de información es la misma que existe entre noticia y opinión o entre hecho y juicio de valor. Empero, estos dos supuestos no se dan siempre en un estado puro, sino que tienden a entrelazarse, tan es así que en la práctica no es común la difusión de noticias con carácter neutral o sin una carga de valoración. La razón es lo complicado de difundir opiniones desvinculándolos de plano de algún hecho.

Los Órganos de la Convención se establecen en el capítulo VI y consisten en la Conferencia de las Partes (artículo 22); Comité Intergubernamental (artículo 23), y Secretaría de la UNESCO (artículo 24). ${ }^{10}$

\section{DERECHO A LA INFORMACÍON}

¿Cómo opinar si no se conoce qué sucede, por qué, cómo, cuándo, dónde? Es imposible participar de manera consiente, reflexiva en las decisiones públicas cuando no se tiene acceso a la información, pero además permite fiscalizar las tareas de los órganos del Estado, por ello es un derecho fundamental de orden público principalmente, ya que es de todos, no es patrimonio individual ni de algún grupo, es menester señalar que el derecho a la información comprende la libertad de buscar, recibir y difundir datos e ideas de toda índole.

\footnotetext{
${ }^{9}$ RODRÍGUEZ LOZANO, Luis Gerardo, La libertad de expresión como requisito esencial para la garantía de las libertades informativas, Fontamara, México, 2015, p. 41.

${ }^{10}$ Convención sobre la protección y la promoción de la diversidad de las expresiones culturales [en línea] 2005. Disponible en http://www.unesco.org/new/es/culture/themes/cultural-diversity/culturalexpressions/the-convention/convention-text/. Acceso 27 ago. 2019.
} 
El acceso a la información se distingue de otros derechos intangibles por su doble carácter: como un derecho en sí mismo y como un medio o instrumento para el ejercicio de otros derechos. En efecto, además de un valor propio, la información tiene uno instrumental que sirve como presupuesto del ejercicio de otros derechos y como base para que los gobernados ejerzan un control respecto del funcionamiento institucional de los poderes públicos, por lo que se perfila como un límite a la exclusividad estatal en el manejo de la información y, por ende, como una exigencia social de todo Estado de derecho. Así, el acceso a la información como garantía individual tiene por objeto maximizar el campo de la autonomía personal, posibilitando el ejercicio de la libertad de expresión en un contexto de mayor diversidad de datos, voces y opiniones; incluso algunos instrumentos internacionales lo asocian a la libertad de pensamiento y expresión, a las cuales describen como el derecho que comprende la libertad de buscar, recibir y difundir informaciones e ideas de toda índole. Por otro lado, el acceso a la información como derecho colectivo o garantía social cobra un marcado carácter público en tanto que funcionalmente tiende a revelar el empleo instrumental de la información no sólo como factor de autorrealización personal, sino como mecanismo de control institucional, pues se trata de un derecho fundado en una de las características principales del gobierno republicano, que es el de la publicidad de los actos de gobierno y la transparencia de la administración. Por tanto, este derecho resulta ser una consecuencia directa del principio administrativo de transparencia de la información pública gubernamental y, a la vez, se vincula con el derecho de participación de los ciudadanos en la vida pública, protegido por la Constitución Política de los Estados Unidos Mexicanos ${ }^{11}$.

En algunos supuestos el ejercicio de la libertad de expresión puede generar cierta tensión para los magistrados o jueces que se encuentran tramitando procesos de alto impacto para la sociedad, al grado de denostarlos por el alcance de sus fallos, ante el conocimiento mediático de las causas.

La Corte IDH ha advierto que puede existir una tensión entre el ejercicio de la libertad de expresión y la independencia judicial. En ese sentido, por una parte, la Corte ha destacado la importancia del ejercicio de la libertad de expresión en una sociedad democrática, inclusive respecto a actos de funcionarios públicos, quienes están más expuestos al escrutinio y a la crítica. De modo análogo, también resulta importante que los funcionarios públicos puedan ser

11 Tesis: P. / J. 54/2008, Semanario Judicial de la Federación y su Gaceta, Tomo XXVII, junio de 2008, p. 743.

Revista Eletrônica do Curso de Direito da UFSM www.ufsm.br/revistadireito v. 14, n. 3 / 2019 e40340 
denunciados o investigados por la posible comisión de actos ilícitos. Todo lo anterior, por otra parte, no implica que el honor de los funcionarios públicos no deba ser protegido, como tampoco que ciertas expresiones, por sus características, puedan resultar intimidatorias o constituir presiones indebidas sobre la actividad judicial ${ }^{12}$.

\section{EJERCICIO DEL PERIODISMO EN MÉXICO}

El ejercicio del periodismo en México puede analizarse desde diferentes perspectivas, en los extremos, se encuentran los que en contubernio con el Estado distorsionan la realidad y por el otro, los medios independientes y críticos, quienes desarrollan su actividad al estilo de los carteles más poderosos: plata o plomo.

La Corte IDH ha señalado que los medios de comunicación son verdaderos instrumentos de la libertad de expresión, que sirven para materializar este derecho y que juegan un papel esencial como vehículos para el ejercicio de la dimensión social de esta libertad en una sociedad democrática, razón por la cual es indispensable que recojan las más diversas informaciones y opiniones. En efecto, la Corte IDH coincide con la Comisión IDH respecto a que los medios de comunicación son, generalmente, asociaciones de personas que se han reunido para ejercer de manera sostenida su libertad de expresión, por lo que es inusual en la actualidad que un medio de comunicación no esté a nombre de una persona jurídica, toda vez que la producción y distribución del bien informativo requieren de una estructura organizativa y financiera que responda a las exigencias de la demanda informativa. De manera semejante, así como los sindicatos constituyen instrumentos para el ejercicio del derecho de asociación de los trabajadores y los partidos políticos son vehículos para el ejercicio de los derechos políticos de los ciudadanos, los medios de comunicación son mecanismos que sirven al ejercicio del derecho a la libertad de expresión de quienes los utilizan como medio de difusión de sus ideas o informaciones ${ }^{13}$.

\footnotetext{
${ }^{12}$ CORTE IDH. Caso Villaseñor Velarde y otros Vs. Guatemala. Fondo, Reparaciones y Costas. Sentencia de 5 de febrero de 2019. Serie C No. 374, Párrafo 86.

${ }^{13}$ CORTE IDH. Caso Granier y otros (Radio Caracas Televisión) Vs. Venezuela. Excepciones Preliminares, Fondo, Reparaciones y Costas. Sentencia de 22 de junio de 2015. Serie C No. 293, Párrafo 148.
} 


\subsection{Plata}

Para darse una idea del monto que se manejó sólo el poder ejecutivo en México por concepto de publicidad y gastos de comunicación entre 2013 a 2018, se entregaron recursos que alcanzan un monto de mil 81 millones 715 mil 991 pesos $^{14}$.

En cuanto a la complicidad para manipular los sucesos políticos, por ejemplo, en los sexenios de Felipe Calderón (2006-2012) y Enrique Peña Nieto (2012- 2018) se entregó a empresas relacionadas con el periodista López-Dóriga, denominado el Maestro, un total de 208 millones de pesos.

Con el gobierno de Felipe Calderón, López-Dóriga se aseguró 46 millones de pesos que lo convirtió en uno de los comunicadores mejores pagados de América Latina. Con Peña Nieto mejoró sus ingresos, durante su sexenio recibió 162 millones pesos ${ }^{15}$.

Este tipo de "periodismo" se enriquece por difundir propaganda política que busca manipular la opinión por medio de noticias falsas, parciales o segadas, con un grave deterioro al sistema democrático al trasgredir el derecho a la información serio y veraz.

\subsection{Plomo}

Reporteros Sin Fronteras (RSF) en el ranking de los países más peligrosos para ejercer el periodismo, hasta abril de 2019 informó que México subió del lugar 147 al 144, pero en América Latina sigue siendo el peor $^{16}$. En total, en los dos sexenios pasados, las agresiones contra periodistas mexicanos sumaron 116: 102 asesinatos y 14 desapariciones; en lo que va del gobierno de Andrés Manuel López Obrador 7 homicidios, lo cual, pone a México como el país más peligroso de América Latina para ejercer esta labor.

\footnotetext{
${ }^{14} \mathrm{Cfr}$. La Verdad, Véase en: https://laverdadnoticias.com/mexico/Periodistas-que-recibieron-MORDIDITAde-Pena-Nieto-Lopez-Doriga-era-su-favorito-20190523-0166.html. Acesso em: 12 jul. 2019.

15 SAAVEDRA, Luis, Joaquín López-Dóriga obtuvo 162 millones en contratos del gobierno de Peña Nieto, Breaking, Véase en: https://breaking.com.mx/2018/05/joaquin-lopez-doriga-microfono-mas-caro-delsexenio/. Acesso em: 12 jul. 2019).

${ }^{16} \mathrm{Cfr}$. GALVAN, Melisa, México es el país más peligroso de AL para ejercer el periodismo: RSF, Expansión Política. Disponível em: https://politica.expansion.mx/mexico/2019/04/20/mexico-es-el-pais-maspeligroso-de-al-para-ejercer-el-periodismo-rsf. Acesso em: 15 jul. 2019).
} 
RSF calificó a México como "patria de los cárteles de la droga”, donde, refirió, que si los periodistas cubren temas relacionados con el crimen organizado o la corrupción de las autoridades (sobre todo en los gobiernos locales), son víctimas de intimidaciones y corren el riesgo de ser asesinados a sangre fría.

Al grado, que el reporte de la Libertad de Prensa, donde hay alrededor de 45 países que son considerados con "situación difícil", entre ellos Afganistán y Paquistán, que aunque viven abiertamente en guerra, el gremio está en mejores condiciones que en México.

En 2018, en México se registraron 544 agresiones a periodistas, un promedio de 1.5 casos al día, y el asesinato de nueve periodistas y dos voceadores, según lo dio a conocer la organización civil Artículo 19. ${ }^{17}$

\subsection{Mecanismos de protección a los periodistas}

Desde 2012 el gobierno ha creado diversos mecanismos para proteger a los defensores de derecho humanos y a los periodistas, el cual obviamente no ha sido eficaz, entre otras causas, por la falta de recurso y falta de coordinación entre las autoridades de los tres niveles de gobierno. La Oficina en México del Alto Comisionado de las Naciones Unidas (OMACNU) para los Derechos Humanos, emitió diagnóstico sobre el funcionamiento de los mecanismos de protección a periodistas, en el que se protegía a 903 personas hasta el 30 de abril de 2019; al respeto la Secretaría de Gobernación prevé que para final de año estará protegiendo a 1,131 beneficiarios lo que implicaría un gasto de 325 millones de pesos ${ }^{18}$.

OMACNU alertó de una insuficiencia en los funcionarios que operan los mecanismos, solamente se cuenta con 36 , cada persona que realiza funciones de seguimiento debe atender un promedio de 155 personas beneficiarias y al 24 de abril estaban pendientes 114 reevaluaciones y 22 evaluaciones, lo que representa un rezago de tres meses de trabajo. ${ }^{19}$

\footnotetext{
${ }^{17} \mathrm{Cfr}$. Periodistas en riesgo: en 2018, se registraron en promedio 1.5 agresiones al día, Expansión Política, Véase en https: //politica.expansion.mx/mexico/2019/04/02/periodistas-en-riesgo-en-2018-se-registraronen-promedio-1-5-agresiones-al-dia. Acesso em: 15 jun. 2019).

${ }_{18}$ VELAZQUEZ, MARISOL, Detectan fallas en mecanismo de protección de periodistas, El Economista, Véase en: https://www.eleconomista.com.mx/politica/Detectan-fallas-en-mecanismo-de-proteccion-deperiodistas-20190822-0014.html. Acesso em: 15 jun. 2019.

${ }^{19}$ Ibidem.
} 


\section{NOTICIAS FALSAS}

Las noticias falsas (fake news) son la invención de hecho que no sucedieron o la alteración de hechos reales con la finalidad de crear confusión y contrarrestar directa e indirectamente a una persona o personas o políticas emprendidas por el gobierno o rivales políticos. Se puede diferenciar entre dos tipos principales; fake news para manipular elecciones a corto plazo y fake news para manipular el debate público y la acción política a medio y largo plazo ${ }^{20}$.

Por ejemplo, López Doriga quien ha dejado de verse favorecido por el actual gobierno (2018-2024), por lo que ahora ha llegado al grado de publicar noticias falsas mal intencionadas, como es el caso tan obvio que realizó al compartir en su cuenta de twitter la denuncia de un investigador argentino que realizo por la falta de apoyo de la institución correspondiente de su país, el Consejo Nacional de Investigaciones Científicas y Tecnológicas (CNICT), pretendiendo desacreditar al Consejo nacional de Ciencia y Tecnología (CONACYT) de México ${ }^{21}$.

Pero las noticias falsas también han alcanzado a la ciencia, como difundir medicamentos milagrosos, grupos anti-vacunas, negación del cambio climático, anti-teorías de la evolución, el negar los sucesos como el Holocausto e ideas respecto a la supremacía racial.

En enero de 2015, respecto del caso de Ayotzinapa el titular de la Procuraduría General de la Republica, Jesús Murillo Karam, dio a conocer que los 43 estudiantes fueron asesinados, que la Policía de Iguala los detuvo y los entregó a un grupo de sicarios, quienes los mataron y quemaron, en una versión que fue llamada "la verdad histórica", que termino siendo una mentira histórica.

¿Cuáles son los objetivos de difundir noticias falsas? Crear confusión, aspira a controlar el discurso público y la acción política mediante la propaganda política que persigue ganar adeptos o neutralizar opositores, en particular, a través de la manipulación de la opinión pública22.

${ }^{20}$ BACKER, Frederick de, Posverdad y fake news: propaganda y autoritarismo en el siglo XXI. 2019, p. 5. Véase en: http://e-spacio.uned.es/fez/view/bibliuned:masterFilosofiaFilosofiaPractica-Fbacker. Acesso em: 16 jul. 2019.

21 Cfr. Conacyt exhibe a Joaquín López Dóriga por difundir 'fake news', MSN Noticias, Véase en https://www.msn.com/es-mx/noticias/mexico/conacyt-exhibe-a-joaqu\%C3\%ADn-l\%C3\%B3pezd\%C3\%B3riga-por-difundir-fake-news/ar-AABDz4M. Acesso em: 12 jul. 2019.

22 BACKER, Frederick de, op., cit., p. 6. 
Las noticias falsas pueden llegar a ser tan nocivas, porque pueden logar decidir una elección, un referéndum o plebiscito

Al grado que se cuestiona la influencia en los resultados de la elección presidencial en Estados Unidos o el voto en Reino Unido para abandonar la Unión Europea (Brexit) de las noticias falsas originadas en páginas web creadas al efecto y difundidas rápidamente a través de las redes sociales $^{23}$.

Un punto que determina que la responsabilidad no es del medio o quien difunde las noticias falsas, sino de la sociedad que no cuestiona y prefiere creer todo lo que se difunda sin reflexión, así las noticias falsas y las burbujas mentales de la gente no son problemas del periodismo, sino de la sociedad. $Y$ esos problemas nunca han tenido soluciones sencillas ${ }^{24}$.

El impacto inmediato en la persona que recibe la información falsa, generalmente de tipo alarmante, es dejarse llevar por las emociones y no por la razón, es decir, a priori determina que es verídico el contenido de la noticia, sin hacer una reflexión, quienes difunden este tipo de "hechos" lo hacen con toda la intención de causar un daño en la reputación y honra de la persona aludida, y en muchos casos lo logran.

De acuerdo con los estudios sobre el análisis del comportamiento humano consideran en primer lugar la subjetividad, ya que al momento de la toma de decisiones el hombre no solamente tiene en cuenta los análisis racionales, sino que dependiendo del momento, la situación y la circunstancia, la carga emocional termina superponiéndose a la lógica de la razón ${ }^{25}$.

Las llamadas "mañaneras" son conferencias de prensa que realiza el Presidente mexicano, todos los días de lunes a viernes principalmente, en el cual se informa de los sucesos relevantes y las políticas públicas que el Estado realiza o pretende realizar, emite réplicas de los reportes o noticias de diversos medios, en éstas distingue a la llamada prensa "fifi", que de acuerdo a su perspectiva es conservadora, para él "Son fantoches, conservadores, sabelotodo, hipócritas, doble cara".

23 PAUNER CHULVI, Cristina. Noticias falsas y libertad de expresión e información. El control de los contenidos informativos en la red. Teoría y Realidad Constitucional, [S.l.], n. 41, p. 297-318, mayo 2018. ISSN 2174-8950. Disponible en: http://revistas.uned.es/index.php/TRC/article/view/22123. Fecha de acceso: 15 maio 2019. doi:https://doi.org/10.5944/trc.41.2018.22123.

${ }^{24}$ CERVERA, José. Contra la verdad, las noticias falsas no existen. Cuadernos de periodistas, 2018, vol. 35, p.6.

${ }^{25} \mathrm{Cfr}$. Emoción y razón, Compartir palabra maestra. Véase en: https://www.compartirpalabramaestra.org/articulos-informativos/emocion-y-razon. Acesso em: 14 maio 2019. 


\section{EL DERECHO A LA VERDAD}

Los elementos estructurales del derecho a la verdad. En primer lugar, es necesario identificar en qué consiste el derecho, o en otras palabras, cuál es el contenido de la obligación que surge del mismo; en segundo lugar, se deben identificar claramente los titulares, tanto de derechos como de obligaciones, y en último lugar, las condiciones adicionales que sean necesarias para su exigibilidad. Así pues, el derecho a la verdad no es un privilegio inherente que se pueda exigir en todo tiempo y circunstancia por todo ser humano ${ }^{26}$.

En caso de lesa humanidad, como lo es la desaparición forzada de personas, constituye un componente esencial del derecho a conocer la verdad a los familiares el conocer el paradero de las víctimas desaparecidas, pues la incertidumbre sobre lo sucedido a sus seres queridos es una de sus principales fuentes de sufrimientos psíquico y moral ${ }^{27}$.

\subsection{Credibilidad}

Actualmente la mayoría de los jóvenes y las otros grupos de la población no ve los noticieros de la televisión, que por mucho tiempo fue la creadores de conciencias y emitieron noticias falsas, segadas, con poca interacción con los televidentes y cómplice del gobierno en turno para manipular toda información que considera el Estado que podría alterar la "seguridad nacional". El actual gobierno de México (2018-2024) ha dejado de pagar publicidad a los medios y a los pseudo periodistas que vivían del presupuesto, lo cual ha generado por un lado el ataque constante de los medios tradicionales por falta de financiamiento público.

Por mucho tiempo se dio de forma descarada una simbiosis entre el poder público y el llamado $4^{\circ}$ poder, que ha tenido como consecuencia la busca de nuevas fuentes de información más creíbles, aunado a la apertura en la web para difundir noticias y opiniones no sujetas al antigua jerarquía de las notas de los acontecimientos por el oligopolio de los medios, pero es necesario desintoxicar al país de las mentiras y vicios que por mucho tiempo imperaron.

\footnotetext{
${ }^{26}$ FAJARDO, Luis Andrés, Elementos estructurales del derecho a la verdad, Civilizar, Ciencias sociales y humanas, 2012, vol. 12, no. 22, p. 19.

${ }^{27}$ Cfr. CORTE IDH. Caso Comunidad Campesina de Santa Bárbara Vs. Perú, párr. 267, y Caso Tenorio Roca y otros Vs. Perú, supra, párr. 244.
} 
Un fenómeno real, es el usos del sistema de youtube para difundir programas de jóvenes o de comunicadores independientes que ha logrado mayor credibilidad para la audiencia juvenil, así en esta plataforma colocan video grabado o en tiempo real y pueden llegar a casi todas las partes del mundo por ser de acceso libre. A estos conductores se les conoce como youtubers como distracción trascedente para las generaciones denominadas Milennials y $\mathrm{Z}$, quienes tienen más credibilidad, interacción y ratings en la audiencia.

\section{CONCLUSIÓN}

Las redes sociales han democratizado no sólo el acceso a la información, sino también la generación de noticias y opiniones que contrastan con los medios tradicionales, sobre todo por permitir la interacción, lo que nos lleva a tener muchas voces sobre una situación, y poder tomar partido de acuerdo a las perspectivas de los hechos y sobre todo en base a la credibilidad del medio o comunicador.

Las noticias falsas (fake news) o pos verdades, la utilización de robots (trolls y bots) son un enemigo difícil de vencer, cuando se busca desprestigiar, porque con éstas provocan una respuesta o posición ante un suceso de manera inmediata, basa en las emociones de los receptores, ante la gran desconfianza social, la verdad requiere tiempo y tomar una posición razonada. Las noticias falsas pueden llegar a ser tan nocivas, porque pueden decidir una elección, un referéndum o plebiscito, atentan directamente al sistema democrático.

El ejercicio del periodismo en México refleja la falta de valores de una descomposición social, por la actuación de los medios tradicionales que se han alimentado y desarrollado al lado del poder, tergiversando los hechos y violando el derecho a la información, actuando más que para difundir sucesos como propaganda política.

Para los periodistas independientes el ejercer la profesión de manera veraz y responsable, representa un grave riesgo para su vida e integridad, víctimas del crimen organizado y de los gobernantes corruptos, en contraste un sistema de justicia que no garantiza ni prontitud ni eficacia para proteger en general a la sociedad.

Así el panorama es crítico, la verdad es una demanda social, la verdad es una necesidad no sólo para juzgar a los responsables de violaciones graves de derechos humanos y realizar la reparación integral a las víctimas, además de generar las garantías de no repetición. 
Muchas son las disposiciones constitucionales, convencionales y legales para proteger los derechos a libertad de pensamiento, expresión, prensa e información, pero poca es la eficacia plena y mínimas las garantías para conocer la verdad.

\section{REFERENCIAS}

BACKER, Frederick de. Posverdad y fake news: propaganda y autoritarismo en el siglo XXI. 2019, p. 5. Véase en: http://e-spacio.uned.es/fez/view/bibliuned:masterFilosofiaFilosofiaPracticaFbacker. Acesso em: 16 jul. 2019.

CERVERA, José. Contra la verdad, las noticias falsas no existen. Cuadernos de periodistas, 2018, vol. 35.

Conacyt exhibe a Joaquín López Dóriga por difundir 'fake news', MSN Noticias, Véase en https://www.msn.com/es-mx/noticias/mexico/conacyt-exhibe-a-joaqu\%C3\%ADn-l\%C3\%B3pezd\%C3\%B3riga-por-difundir-fake-news/ar-AABDz4M. Acesso em: 12 jul. 2019.

CORTE IDH. Caso Comunidad Campesina de Santa Bárbara Vs. Perú, párr. 267, y Caso Tenorio Roca y otros Vs. Perú, supra, párr. 244.

CORTE IDH. Caso Fontevecchia y D A Amico Vs. Argentina. Fondo, Reparaciones y Costas. Sentencia de 29 de noviembre de 2011. Serie C No. 238, Párrafo 50.

CORTE IDH. Caso Granier y otros (Radio Caracas Televisión) Vs. Venezuela. Excepciones Preliminares, Fondo, Reparaciones y Costas. Sentencia de 22 de junio de 2015. Serie C No. 293, Párrafo 148.

CORTE IDH. Caso Granier y otros (Radio Caracas Televisión) Vs. Venezuela. Excepciones Preliminares, Fondo, Reparaciones y Costas. Sentencia de 22 de junio de 2015. Serie C No. 293, Párrafo 143.

CORTE IDH. Caso Lagos del Campo Vs. Perú. Excepciones Preliminares, Fondo, Reparaciones y Costas. Sentencia de 31 de agosto de 2017. Serie C No. 340., Párrafo 89.

CORTE IDH. Caso Villaseñor Velarde y otros Vs. Guatemala. Fondo, Reparaciones y Costas. Sentencia de 5 de febrero de 2019. Serie C No. 374, Párrafo 86. 
CORTE IDH. La Colegiación Obligatoria de Periodistas. Opinión Consultiva OC-5/85.

Emoción y razón, Compartir palabra maestra. Véase en:

https://www.compartirpalabramaestra.org/articulos-informativos/emocion-y-razon. Acesso em: 14 maio 2019.

FAJARDO, Luis Andrés, Elementos estructurales del derecho a la verdad, Civilizar, Ciencias sociales y humanas, 2012, vol. 12, no. 22, p. 19.

GALVAN, Melisa, México es el país más peligroso de AL para ejercer el periodismo: RSF, Expansión Política, Véase en: https://politica.expansion.mx/mexico/2019/04/20/mexico-esel-pais-mas-peligroso-de-al-para-ejercer-el-periodismo-rsf. Acesso em: 15 jul. 2019.

La Verdad, Véase en: https: / /laverdadnoticias.com/mexico/Periodistas-que-recibieronMORDIDITA-de-Pena-Nieto-Lopez-Doriga-era-su-favorito-20190523-0166.html. Acesso em: 12 jul. 2019.

PAUNER CHULVI, Cristina. Noticias falsas y libertad de expresión e información. El control de los contenidos informativos en la red. Teoría y Realidad Constitucional, [S.l.], n. 41, p. 297-318, mayo 2018. ISSN 2174-8950. Disponible en:

http: //revistas.uned.es/index.php/TRC/article/view/22123. Fecha de acceso: 15 maio 2019 .doi:https://doi.org/10.5944/trc.41.2018.22123.

Periodistas en riesgo: en 2018, se registraron en promedio 1.5 agresiones al día, Expansión Política, Véase en https://politica.expansion.mx/mexico/2019/04/02/periodistas-en-riesgo-en2018-se-registraron-en-promedio-1-5-agresiones-al-dia. Acesso em: 15 jun. 2019.

RODRÍGUEZ LOZANO, Luis Gerardo, La libertad de expresión como requisito esencial para la garantía de las libertades informativas, Fontamara, México, 2015.

SAAVEDRA, Luis, Joaquín López-Dóriga obtuvo 162 millones en contratos del gobierno de Peña Nieto, Breaking, Véase en: https: //breaking.com.mx/2018/05/joaquin-lopez-doriga-microfonomas-caro-del-sexenio. Acesso em: 12 jul. 2019.

Tesis: 1a. CCXV/2009, Semanario Judicial de la Federación y su Gaceta, Tomo XXX, diciembre de 2009, p. 287.

Tesis: I.40.C.71 C (10a.), Gaceta del Semanario Judicial de la Federación, Libro 65, abril de 2019, Tomo III, p. 2005.

Tesis: P. /J. 54/2008, Semanario Judicial de la Federación y su Gaceta, Tomo XXVII, junio de 2008, p. 743. 
VELAZQUEZ, MARISOL, Detectan fallas en mecanismo de protección de periodistas, El Economista. Véase en: https://www.eleconomista.com.mx/politica/Detectan-fallas-enmecanismo-de-proteccion-de-periodistas-20190822-0014.html. Acesso em: 22 ago. 2019.

Artigo convidado / Publicado em: 02.10.2019

\section{COMO FAZER REFERÊNCIA AO ARTIGO (ABNT/BRASIL):}

LAZCANO, Alfonso Jaime Martínez. Crisis del derecho a la verdad en México. Revista Eletrônica do Curso de Direito da UFSM, Santa Maria, RS, v. 14, n. 2, e40340, maio/ago. 2019. ISSN 1981-3694. DOI: http://dx.doi.org/10.5902/1981369440340. Disponível em: https://periodicos.ufsm.br/revistadireito/article/view/40340 Acesso em: dia mês. ano.

Direitos autorais 2019 Revista Eletrônica do Curso de Direito da UFSM

Editores responsáveis: Rafael Santos de Oliveira e Angela Araujo da Silveira Espindola

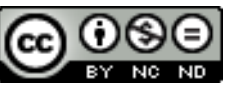

Esta obra está licenciada com uma Licença Creative Commons Atribuição-NãoComercial-SemDerivações 4.0 Internacional.

\section{SOBRE O AUTOR}

ALFONSO JAIME MARTíNEZ LAZCANO

Investigador del Sistema Nacional de Investigadores Conacyt Nivel 1. Doctor en Derecho Público. Profesor e Investigador de la Universidad de Ciencias y Artes de Chiapas, https://orcid.org/0000-0003-0367-4716. Contacto: lazcanoalf14@hotmail.com Chiapas, México. 